\title{
Identification of liquefaction disaster in Jondul Rawang, Padang City West Sumatra
}

\author{
Utami Dewi Arman ${ }^{1 *}$, Rafki Imani $^{1}$, Afrilda Sari $^{1}$, and Widiawati Purba $^{1}$ \\ ${ }^{1}$ Department of Civil Engineering, University of Putra Indonesia YPTK Padang, West Sumatra
}

\begin{abstract}
Liquefaction is a condition of continuous soil mass deformation at residual stress due to increasing pore water pressure that results in effective stress reduced. This study was conducted to identify the potential hazards of liquefaction in the Jondul Rawang area in Padang City. This study is to observe the soil contour and characteristics. Primary data obtained by observing the soil contour, soil characteristics, and the form of buildings, etc. Whilst, secondary data obtained from the related documents as supporting data. The results concluded that the Jondul Rawang area is potentially liquefaction area where the soil contours and characteristics could be classified as peat soil and lied in the swamps. Furthermore, if the rainfall intensity increase then flooding occurred. Then as consequences, there were many residential houses and other buildings around the area turning into tilted and drowned due to the degradation of soil bearing capacity. Therefore, requiring disaster management efforts against the threat of liquefaction in that area, both in terms of the drainage system due to flooding and overall repairs for the sewerage could work well.
\end{abstract}

\section{Introduction}

Indonesia is an archipelago country laid between three huge plates, which are the Eurasian Plate, the IndoAustralian Plate and the Pacific Plate [1]. The meeting point of the three plates is the source of great tectonic earthquakes that frequently hit Indonesian territory. Padang city located in West Sumatra is one region where to be crossed by the three plates. The earthquake in September 2009 that struck most of the coastal areas in West Sumatra killed more than 1,000 people and 10,000 buildings collapsed [2].

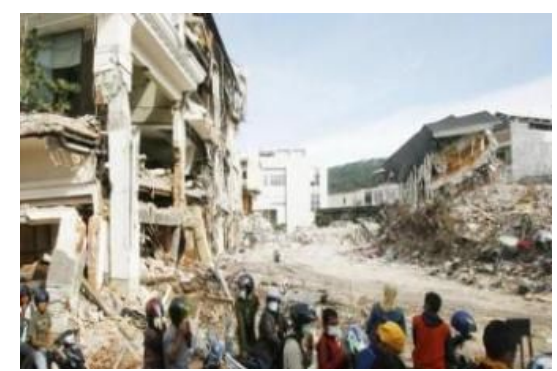

Fig. 1. Buildings collapse due to the Mentawai Earthquake in 2009 [3].

As a result of this earthquake certainly provides valuable lessons for us to be able to increase awareness and preparedness for the impact of the earthquake that might occur in the future. The impact of the earthquake in 2009 had resulted in liquefaction at several points on the coast of Padang, West Sumatra [4], one of which was in the Jondul Rawang area in Padang City.
Based on these facts, in this study identification of potential liquefaction of buildings in the area was conducted.

\subsection{Literature}

\subsubsection{Liquefaction and Earthquake}

An earthquake is a natural phenomenon due to sudden breakdown of rock mass in the ground causing disturbance to the soil stability due to earthquake energy that propagates to the surface so that the soil is no longer able to support the buildings above. The event of decreasing soil mass is called liquefaction [1]. Liquidation is a condition where the soil mass loses its bearing capacity [5].

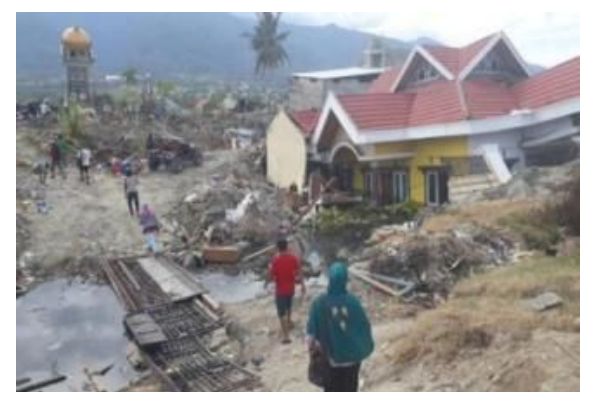

Fig.2. Sinking house in Bolora Housing due to earthquake resulting liquefaction 2018 [6].

The ground is one element of civil structures, which requires stabled-soil conditions that can increase the strength of the buildings. To get well soil conditions, a

\footnotetext{
*Corresponding author: udewi2679@gmail.com
} 
soil investigation is needed that are field and laboratory tests, so that it might be taken into consideration in building construction planning activity. By knowing the soil characteristics, the planner could conclude what the behavior of the soil to be stable and safe. The planners could prevent the risks which could disturb the stability and soil bearing, i.e risks and hazards caused by liquefaction as the secondary impact of an earthquake.

The disasters of liquefaction could result in the tension of the pore water itself. When liquefaction occurs, then the strength of the soil and the ability of the soil deposit to withstand the load decreased. The effective stress of the soil due to the cyclic load received by the soil with grainy characteristics, water saturation, and medium density, resulting in the soil experiences a change in nature from solid to liquid, as consequence occurs damage to residential buildings such as collapse.

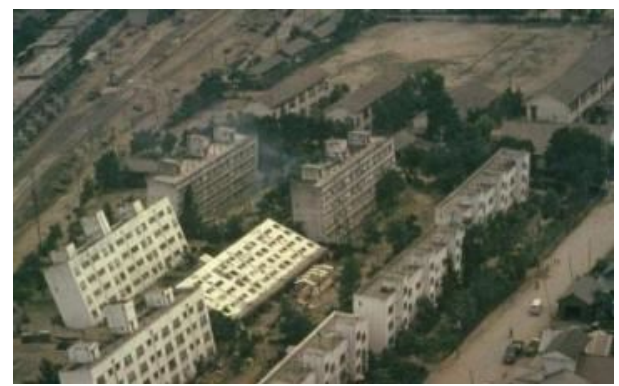

Fig.3.The liquefaction due to the Nigata earthquake in1964 with 6,4 RS magnitude[7].

The liquefaction ever occurred in another country, such as the earthquake in Nigata, Japan in 1964. Reviewing the potential caused by liquefaction, the experts began to develop practical methods to analyze liquefaction potential in the soil. There are some liquefaction analysis methods already exist, one of them is an analysis method using field test data, such as cone penetration test, penetration standard test, boring test, and Swedish test. Besides, liquefaction potential analysis could also be determined based on tests in the laboratory as grain analysis. From some analysis methods, the method that frequently used by experts is the SPT method [8].

\subsubsection{The Cause of Liquefaction}

Through several studies and observations conducted, could be concluded that the behavior of soil liquefaction has the potential to occur in soil deposit that classified as grains with high groundwater levels and medium density. Where soil with characteristics like this tend to become solid due to vibrations that occur in the soil due to the volume decreased [9]. In this phase, pore water flows inside the cavity formed from grain formation cannot occurs on that the pore water pressure increases and when the pore water pressure reaches its limit which has the same value as the soil overcharge pressure than the effective stress of the soil becomes zero and the soil as a whole has lost its power and is in a liquidated condition.
In general, the cause of liquefaction on unconsolidated soil and saturated water during an earthquake is the excessively increasing to hydrostatic pressure due to cyclic shear stresses as consequent from ground movement. This shear stress can cause increases in shear wave propagation in the soil so that the soil structure becomes denser and followed by the displacement of pore water tension and reduced stress on the grain resulting in soil grain trying to maintain its constancy in volume, wherein this condition is an increase in pore water pressure higher in the soil. When the pore water tension reaches the limit pressure, then the sand will change the form. In loose sand, pore water tension will suddenly increase to reach the same high-value with limit pressure, and the sand will change its form quickly with stress-strain is about $20 \%$ or more. If the change of the form continuously without significant durability, the soil could be called becoming liquid.

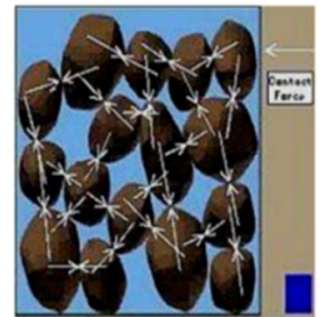

(a)

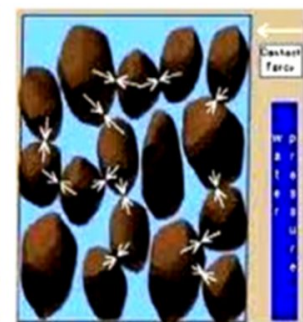

(b)
Fig.4. (a) Soil particles-liquefaction, (b) Soil particles after liquefaction [10].

\subsubsection{Liquefaction Evaluation}

The potential liquefaction of a land deposit will be determined by the combination of several components, including [9]:

1. Soil properties index dynamic modulus, moisture characteristics, volume weight, grain grading, relative density, and soil structure itself.

2. Environmental factors.e the type of land formation, seismic and geological history, groundwater level, and the effective stress of the soil.

3. The characteristic of an earthquake is the intensity of vibration to the ground and the duration of vibration occurred.

Based on some of the factors mentioned above, not all of these factors can be determined directly, but the impact arising from these three factors can be used or input into the evaluation procedure of liquefaction potential, that is conducting a cyclic load test on a soil sample or through measurement of liquefaction-soil characteristics use several test procedures in the field. Standard procedures for liquefaction evaluation include:

1. Determining the amount of cyclic stress arising from ground movement during an earthquake, at each depth of the soil deposit and convert the irregular shape of the stress so that it has the same magnitude in the form of cyclic stress. In other words, the intensity, the duration and the variation of the shake resulted from stress at each depth transformed into a quantity that can be calculated. 
Determination of the amount of cyclic that occurs can be taken by analyzing the response of the soil to the stresses that occur.

2. Determining the amount of cyclic stress using a loading test in a laboratory by an untroubled sample through a predetermined free pressure variation or tolerating properties with characteristics in the field.

3. Comparing shear stresses caused by earthquakes with things that can cause liquefaction to determine whether land deposits are in the liquefaction zone or not. As shown in Fig. 5.

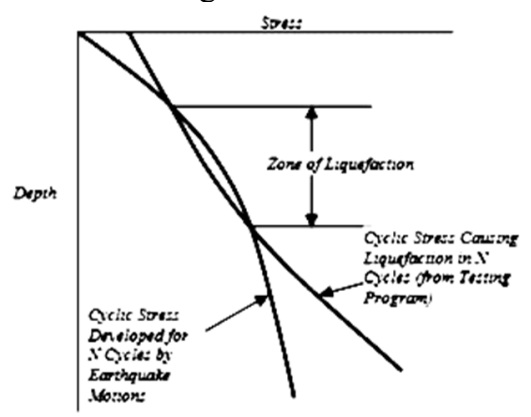

Fig.5. Evaluation method for soil liquefaction potensial [11].

Based on discussed previously, liquefaction behavior on the soil is destructive and has a large negative impact on the stability of the land and buildings on it. The impacts arising from liquefaction behavior are:

1. The decrease up to $5 \%$ of the thickness of the liquefied-soil layer.

2. The loss of lateral soil bearing capacity.

3. The loss of soil bearing capacity.

4. The occurrence of the location of structures embedded in the ground, such as underground tanks.

5. The lateral soil pressure increase that could cause failure in the structure of the lateral pressure retaining.

6. The occurrence of lateral spreading (limited-lateral movements).

7. The occurrence of lateral-flow (extensive lateral movements)

\subsection{Study Area}

The study area is in the Jondul Rawang Housing in Padang City. This area laid on the coast of Padang precisely in the District of South Sumatra, West Sumatra. This area was once a ricefield the area which was used as a residential area. This area has very low water absorption capacity.

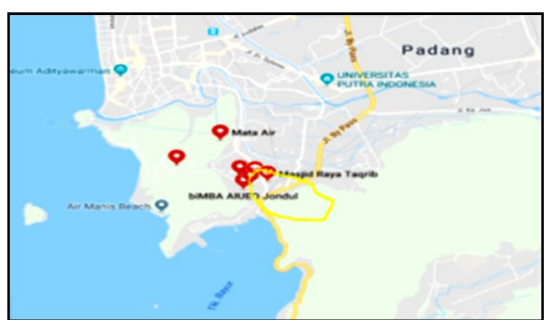

Fig.6.The Map of Study Area [13].
Jondul Rawang village, South Padang District is a low-land area. Frequent flooding due to high rainfall intensity and lack of water absorption capacity in the soil results in decreasing the carrying capacity of the soil to buildings as a result of decreasing rock mass in the soil. Besides, the lack of a drainage system has also increased the risk of high flooding in the area [12].

\section{Methodology}

This research method conducted through direct observation and literature study as supporting material. The data needed are primary and secondary. Primary data is such as data collected directly from the study areas which are soil types and building forms in the study area. Whilst secondary data obtained from relevant instances that are rainfall data and population data.

The systematical observation process and recording of the symptoms or situation in the study area through conducting a direct observation. Primary data is the data collected directly from the field such as data soil contours, the form of buildings that are on the ground surface at the location, and others related to this study. Secondary data obtained from the Agency for Water Resources Management (PSDA), namely rerainfall in 2005 - 2015. Secondary data were taken from the Central Statistics Agency Padang City in 2015 [14], such a general description of Padang City, location of the Padang city areas and others related to this study.

\section{Discussions}

\subsection{The types of Soil in Study Area}

Following observation in the field, the type of soil at that location is peat soil. Peat soil is formed from the accumulation of residues from plants that are halfrotted or undergoing incomplete decomposition [15]. The type of soil in the observation location also has a lot of water content, as indicated in the Jondul Rawang Housing is a swampland that heaped up by the developer for the construction of housing (based on the interviews with the residents). The location under these conditions is very susceptible to the risk of liquefaction during an earthquake in Padang city.

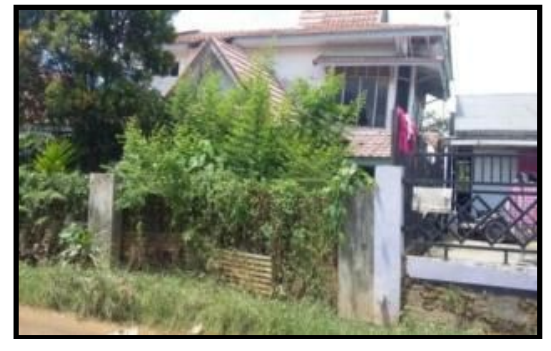

Fig.7. The degradation of soil bearing capacity 


\subsection{The Description of the Buildings in Study Area}

The description of the buildings in the Jondul Rawang Housing is the group of buildings that have several supermarkets or minimarkets owned by people. Fig. 8 shows the supermarket due to the changes of land subsidence in the study area. It shows the abandoned supermarket with a puddle of water due to the lack of water shrinkage in the location. The plants that grow in this location are needle grass_indicating that soil type is grainy.

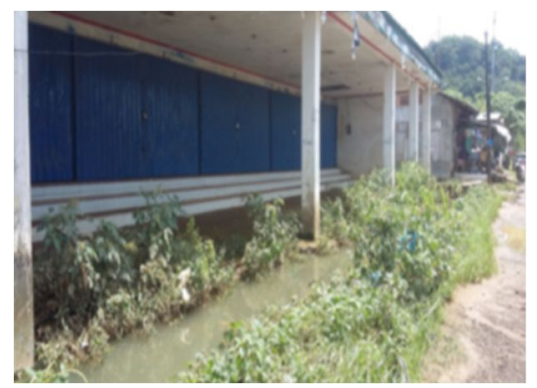

Fig.8. The condition of supermarket due to land subsidence

\subsection{The Drainage System in Study Area}

Besides soil degradation caused by the soil bearing capacity, the other causes are also caused by substandard drainage conditions in the housing (Fig. 9). In the picture, this below can be shown that the drainage system in the housing, which it's quite unworthy and the elevation of the drainage slope. It is caused by the process of land subsidence yearly. If the intensity of the rainfall is very high, it will enable the area to be very susceptible to flood disasters.

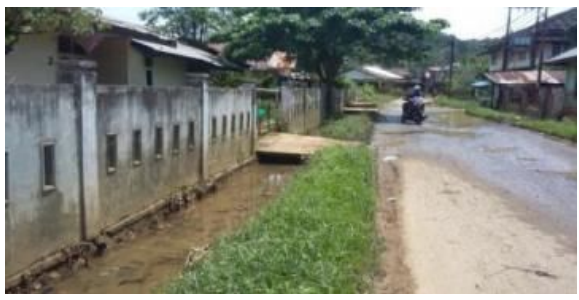

Fig.9.The degradation of the drainage canal

\subsection{Problem Solving}

As for substandard drainage system issues, it is necessary to have a good process of improvement and drainage planning. As the authors visited the study area found that there was a process of renovation on the drainage system. These repairs aimed to control water capacity during heavy rainfall and can prevent flooding in the future (Fig. 10).

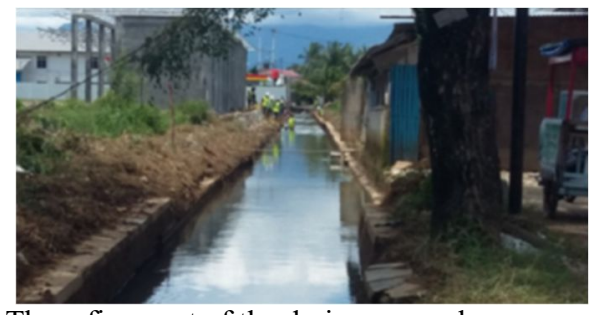

Fig.10.The refinement of the drainage canal

\section{Conclusions}

Based on the discussion above, it could be made many conclusions as follows:

1. Soil liquefaction potential could be occurred at the Jondul Rawang area, based on its contour, morphology (near the coast) and soil properties in the area. Based on secondary data, the type of soil is organosol/peat soil which is grainy soil and lied in the swamps.

2. Besides the risk of liquefaction, the Jondul Rawang Housing is also a flood-susceptible area, if the rainfall intensity is very high where resident houses and other buildings will form a puddle of water and water shrinkage less.

3. The recommendations for this study are in terms of the substandard drainage system, the strength of building structure, soil improvement method of peat soil and maintain the coastal area near the area study.

\section{References}

1. Tini., A. Tohari., M. Iryanti. Wahana Fisika. 2 (1), 8-27 (2017)

2. http://www.bbc.com

3. http://www.merdeka.com

4. A. Hakam., H. Darjanto. Jurnal Teknik Sipil. 20 (1), 33-38 (2017)

5. F. Zettyara., Harimurti., Y. Zaika. Jurnal Mahasiswa Jurusan Teknik Sipil Universitas Brawijaya. 2 (2), 631 (2018)

6. http://www.jurnalsulawesi.com

7. http://www.google.com

8. S.A. Khan., Z. Saeed., A. Khan., G. Hamid., S.W. Haider, Int. J. Econ. Environ. Geol. 8 (2), 63-68 (2017)

9. A. Setianto., Soetoto. Jurnal Geodesi UGM (cgise.geodesi.ugm.ac.id)

10. http://www.likuifaksitanah.com

11. http://www.ground-motion-and-soil-liquefactionduring-earthquake.com

12. http://www.news.klikpositif.com

13. Badan Pusat Statistik Kota Padang Tahun 2015

14. D. Noor. Geologi untuk Perencanaan (Graha Ilmu, Yogyakarta, 2011) 